Article

\title{
Effects of Impactor Size on Biomechanical Characteristics of Spinal Cord in Hemicontusion Injury Model Using Finite Element Analysis
}

\author{
Batbayar Khuyagbaatar ${ }^{1,2,+}$, Kyungsoo Kim ${ }^{3, \dagger}$, Temuujin Batbayar ${ }^{1}$ and Yoon Hyuk Kim ${ }^{1, *}$ \\ 1 Department of Mechanical Engineering, Kyung Hee University, Yongin 17104, Korea; \\ batbayarkh@must.edu.mn (B.K.); temuujin@khu.ac.kr (T.B.) \\ 2 Department of Technical Mechanics, Mongolian University of Science and Technology, \\ Ulaanbaatar 14191, Mongolia \\ 3 Department of Applied Mathematics, Kyung Hee University, Yongin 17104, Korea; kyungsoo@khu.ac.kr \\ * Correspondence: yoonhkim@khu.ac.kr \\ + Batbayar Khuyagbaatar and Kyungsoo Kim contributed equally to this work as first authors.
}

Received: 3 May 2020; Accepted: 12 June 2020; Published: 14 June 2020

\begin{abstract}
A cervical hemicontusion spinal cord injury (SCI) produces forelimb deficits on the ipsilateral side of the injury while sparing the function of the limbs on the contralateral side of the injury, allowing for the evaluation of experimental therapeutics for functional recovery. Although the effects of contusion force on the functional and behavioral outcomes were adequately described in previous experimental studies, the size of the impactor tip also had significant effects on the extent of the lesion on the contralateral side of the injury in the hemicontusion rat model. However, studies regarding the effects of impactor size on the spinal cord for the hemicontusion model are limited. In this study, a finite element (FE) model of the rat cervical spinal cord was developed to investigate the effects of impactor size in the hemicontusion SCI model on the stress, strain, and displacement of the spinal cord for the New York University (NYU) and Infinite Horizon (IH) impactors. The impactor tip diameters of $1.2 \mathrm{~mm}$ and $1.6 \mathrm{~mm}$ with high impact loading resulted in the highest stresses and strains in the right (ipsilateral) side of the spinal cord. Thus, impactor tip diameters between $1.2 \mathrm{~mm}$ and $1.6 \mathrm{~mm}$ would be convenient to use in the rat hemicontusion SCI models for the cervical region without damaging the left (contralateral) side of the spinal cord. Our findings provide an insight into SCI mechanisms in the rat cervical hemicontusion model.
\end{abstract}

Keywords: impactor; hemicontusion; spinal cord injury; finite element analysis; biomechanics

\section{Introduction}

Most human spinal cord injuries (SCIs) occur in the cervical region [1]. However, several experimental contusion SCI models have been developed to study injury in the thoracic spinal cord [2-8] due to their reliability and reproducibility [9]. Thus, how findings in experimental injury models in the thoracic region are applicable to human cervical SCIs is questionable because the functional deficits and symptoms are significantly different for these two injury levels $[10,11]$. Contusion injuries damage both white and gray matter at either the cervical or thoracic region. However, their functional consequences are more related to white matter [12]. Therefore, some attempts have been made to characterize contusion injury models in the cervical spinal cord in rats or mice [10,13-15], including cervical hemicontusion injuries [9,11,12,16-18]. Reportedly, cervical hemicontusion injuries produce forelimb deficits on the ipsilateral side of the injury while sparing the function of the limbs on the contralateral side of the injury $[9,12,16,17]$, allowing for the efficacy of experimental therapeutics for upper limb functional recovery to be evaluated [18] 
Several devices are available for contusion injuries including the Ohio State University (OSU) device [2], the New York University (NYU) impactor [3], the Infinite Horizon (IH) impactor [5], and the Leica Impact One Stereotaxic Impactor [19]. The IH impactor has been utilized in numerous studies $[11,15-17,20]$, and the NYU impactor or weight drop device has been used in several studies for cervical hemicontusion SCI models with some modifications [9,12,21]. Mondello et al. [18] modified the OSU device for a lateralized cervical contusion in rats. To produce unilateral cervical injuries, some of the device parameters required adjustments, including of the impactor tip diameter and off-center distances, since these devices were originally developed for thoracic injuries. Gensel et al. [12] performed unilateral cervical injuries with a modified $2.0 \mathrm{~mm}$ impactor using the 6.25 and $12.5 \mathrm{~mm}$ weight-drop contusion model. The experimental studies that utilized the IH impactor for the hemicontusion injury rat model used impact forces ranging from $100 \mathrm{kdyn}$ to $395 \mathrm{kdyn}$ with impactor tips $0.8 \mathrm{~mm}$ to $1.6 \mathrm{~mm}$ in diameter $[11,15,16,20,22]$. Although the effects of contusion force on the functional and behavioral outcomes were adequately described in previous experimental studies [11,12], the size of the impactor tip also had significant effects on the extent of the lesion on the contralateral side in the hemicontusion rat model [12].

Due to the limitations associated with experimental pre-clinical research, finite element (FE) analysis has been used to investigate the relationship between spinal cord tissue mechanics and neurological injury [23-30]. The FE model of the rat spinal cord was developed to simulate the weight-drop contusion model, including the off-center impact on the spinal cord [23], and to investigate strains in the cervical region during contusion and dislocation injuries [28]. Moreover, the impact depth was shown to be the most important factor in determining the injury severity in rats [30]. Recently, the correlation between impact parameters in the NYU and IH impactors was investigated using the mid-thoracic spinal cord rat model [31]. In addition, a non-human primate unilateral cervical contusion injury model was developed by Sparrey et al. [32], and a murine lateral cervical contusion model was presented by Fournely et al. [33]. However, studies regarding the effects of impactor size on the spinal cord for the hemicontusion model are limited. In this study, we investigated the effects of impactor size on the biomechanical characteristics of the spinal cord in a hemicontusion injury model for the NYU and IH impactors using the FE model of the rat spinal cord in the cervical region.

\section{Materials and Methods}

The FE model of the rat cervical spinal cord was developed based on a previously validated model [31]. The geometry of the rat spinal cord was obtained from an in vivo imaging study [34]. The developed model consists of white and gray matter, the dura mater, and the CSF (cerebrospinal fluid) layer (Figure 1). The length of the spinal cord was $14 \mathrm{~mm}$, the same as in a previous modeling study [23]. In total, the model comprised 201,826 nodes and 172,716 hexahedron elements except the CSF layer. The CSF layer was modeled as fluid elements surrounding the spinal cord using ABAQUS/Explicit (ABAQUS Inc., Providence, RI, USA). The details of the fluid modeling technique can be found in the previous study [31]. Furthermore, the simplified spinal canal was modeled based on anatomical measurements of the rat cervical spinal canal to mimic the experiment [35]. The frictionless contact was applied between the cord, the CSF layer, and the dura mater due to the lubricating effect of fluid inside the dural sheath, while the friction coefficient between the dura mater and impactor as well as the spinal column was 0.15 based on a previous study [23]. The material properties of the white and gray matter and dura mater were hyperelastic-viscoelastic [23]. The CSF layer was modeled with a Newtonian fluid with a viscosity of $0.001 \mathrm{pa} \cdot \mathrm{s}$ [36]. 

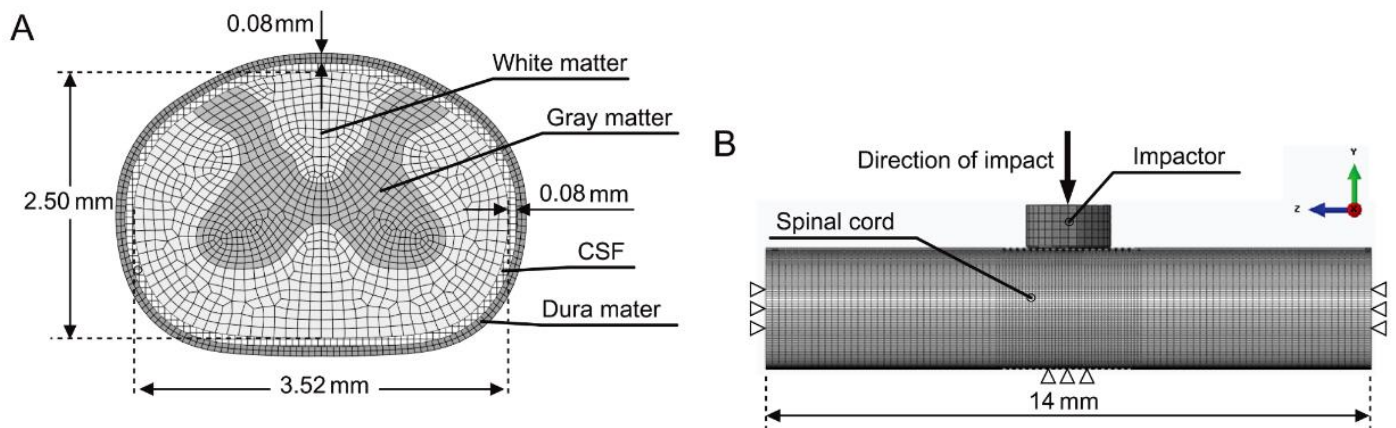

Figure 1. (A) Axial view of the cervical spinal cord in the rat finite element (FE) model. (B) Sagittal view of the spinal cord model with an impactor.

Two different (NYU and IH impactor) hemicontusion SCI models were simulated with the four differently sized impactor rods. The rods were modeled with diameters of $0.8 \mathrm{~mm}, 1.2 \mathrm{~mm}, 1.6 \mathrm{~mm}$, and $2.0 \mathrm{~mm}$ and placed $1.0 \mathrm{~mm}$ to the right side of the spinal cord to simulate the hemicontusion injury models (Figure 2), which was approximately centered over the right side of the spinal cord based on previous experimental studies [12,16]. In the NYU model, the four different impactor rods were the same weight of $10 \mathrm{~g}$ and placed in direct contact with the spinal cord [31]. Then, the predefined initial velocities were applied to the impactor rods for drop heights of 6.25 and $12.5 \mathrm{~mm}$ cases [31]. In the IH model, the impactor rods were the massless cylindrical body and loaded with forces of $100 \mathrm{kdyn}$ and $200 \mathrm{kdyn}$ with a velocity of $125 \mathrm{~mm} / \mathrm{sec}$ to replicate the experimental condition [5]. In total, eight replicates were simulated in each impactor. The von-Mises stress and maximum principal strain for the right (ipsilateral) and left (contralateral) sides of the spinal cord, and spinal cord displacement were analyzed for two different (NYU and IH impactor) models with four differently sized impactors using FE analysis. The right and left sides of the spinal cord were determined by dividing the spinal cord at the midline. The spinal cord displacement was estimated from the impactor rod motion [31]. A two-way ANOVA was performed to compare the stresses and strains on the right and left sides of the spinal cord. A one-way ANOVA was also employed to analyze the maximum displacement of the spinal cord. The significance level was set at $p<0.05$.
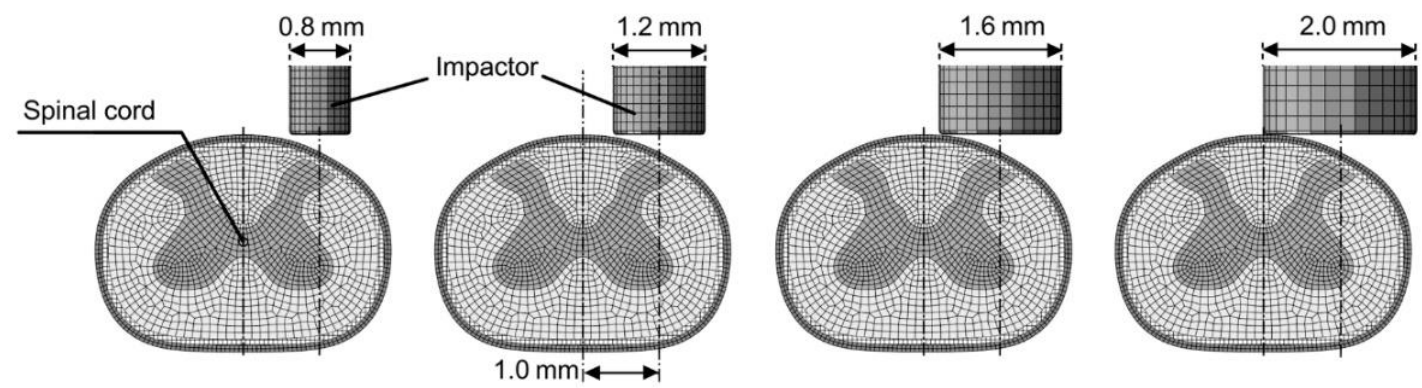

Figure 2. Spinal cord with four different impactors which were moved $1.0 \mathrm{~mm}$ to the right side of the midline, which was approximately centered over the right side of the spinal cord.

\section{Results}

The von-Mises stress in the cord increased as the impact height or force increased for both impactors, and the impactor tip diameter of $1.6 \mathrm{~mm}$ resulted in the highest stress in the cord on the right (ipsilateral) side the spinal cord. By contrast, the von-Mises stresses were decreased with larger impactors at a drop height of $6.25 \mathrm{~mm}$ for the NYU impactor and an impact force of $100 \mathrm{kdyn}$ for the IH impactor. The stresses on the right (ipsilateral) side were significantly higher than on the left (contralateral) side of the spinal cord $(p<0.05)$ (Figure 3a). On the contralateral side, the von-Mises stresses were slightly increased with the larger impactor diameters, regardless of which impactor 
(NYU or IH) was used (Figure 3a). For the NYU impactor, the stresses in the cord were $0.55 \mathrm{MPa}$, $0.38 \mathrm{MPa}, 0.35 \mathrm{MPa}$, and $0.32 \mathrm{MPa}$ at the drop heights of $6.25 \mathrm{~mm}$, and $0.79 \mathrm{MPa}, 0.93 \mathrm{MPa}, 1.12 \mathrm{MPa}$, and $0.79 \mathrm{MPa}$ at the drop height of $12.5 \mathrm{~mm}$, with $0.8 \mathrm{~mm}, 1.2 \mathrm{~mm}, 1.6 \mathrm{~mm}$, and $2.0 \mathrm{~mm}$ diameters, respectively. Under experimental conditions for the $\mathrm{IH}$ impactor, the stresses were $0.57 \mathrm{MPa}, 0.37 \mathrm{MPa}$, $0.29 \mathrm{MPa}$, and $0.21 \mathrm{MPa}$ with $100 \mathrm{kdyn}$ and $0.77 \mathrm{MPa}, 0.97 \mathrm{MPa}, 1.19 \mathrm{MPa}$, and $0.8 \mathrm{MP}$ with $200 \mathrm{kdyn}$ impact forces, with $0.8 \mathrm{~mm}, 1.2 \mathrm{~mm}, 1.6 \mathrm{~mm}$, and $2.0 \mathrm{~mm}$ diameters, respectively (Figure 3a). The stress distributions in the transverse views at the maximum compression are shown in Figure 4. Similarly, the maximum principal strains peaked at the $1.6 \mathrm{~mm}$ diameter impactor on the ipsilateral side with the $12.5 \mathrm{~mm}$ NYU impactor and $200 \mathrm{kdyn} \mathrm{IH}$ impactor, and decreased with the larger impactor diameter under low impact loading conditions (Figure $3 b$ ). A significant difference was observed between the right and left side of the spinal cord $(p<0.05)$ (Figure 3b). Higher strains were mostly located on the ipsilateral side, regardless of the load and impactor tip diameter (Figure 5).

The maximum spinal cord displacement was gradually reduced as the impactor tip diameter increased, regardless of which impactor was used (Figure 6). The smaller impactor tip diameters caused higher displacement, but the spinal cord was likely to shift laterally. The maximum displacements were $2.3 \mathrm{~mm}, 2.2 \mathrm{~mm}, 2.1 \mathrm{~mm}$, and $1.9 \mathrm{~mm}$ for impactor tip diameters of $0.8 \mathrm{~mm}, 1.2 \mathrm{~mm}, 1.6 \mathrm{~mm}$, and $2.0 \mathrm{~mm}$, respectively. There was no significant difference in the spinal cord displacement according to the impactor tip diameter $(p=0.10)$. Based on the results, the $6.25 \mathrm{~mm}$ and $12.5 \mathrm{~mm}$ conditions of the NYU impactor were similar to the $100 \mathrm{kdyn}$ and $200 \mathrm{kdyn}$ conditions of the IH impactor, respectively.
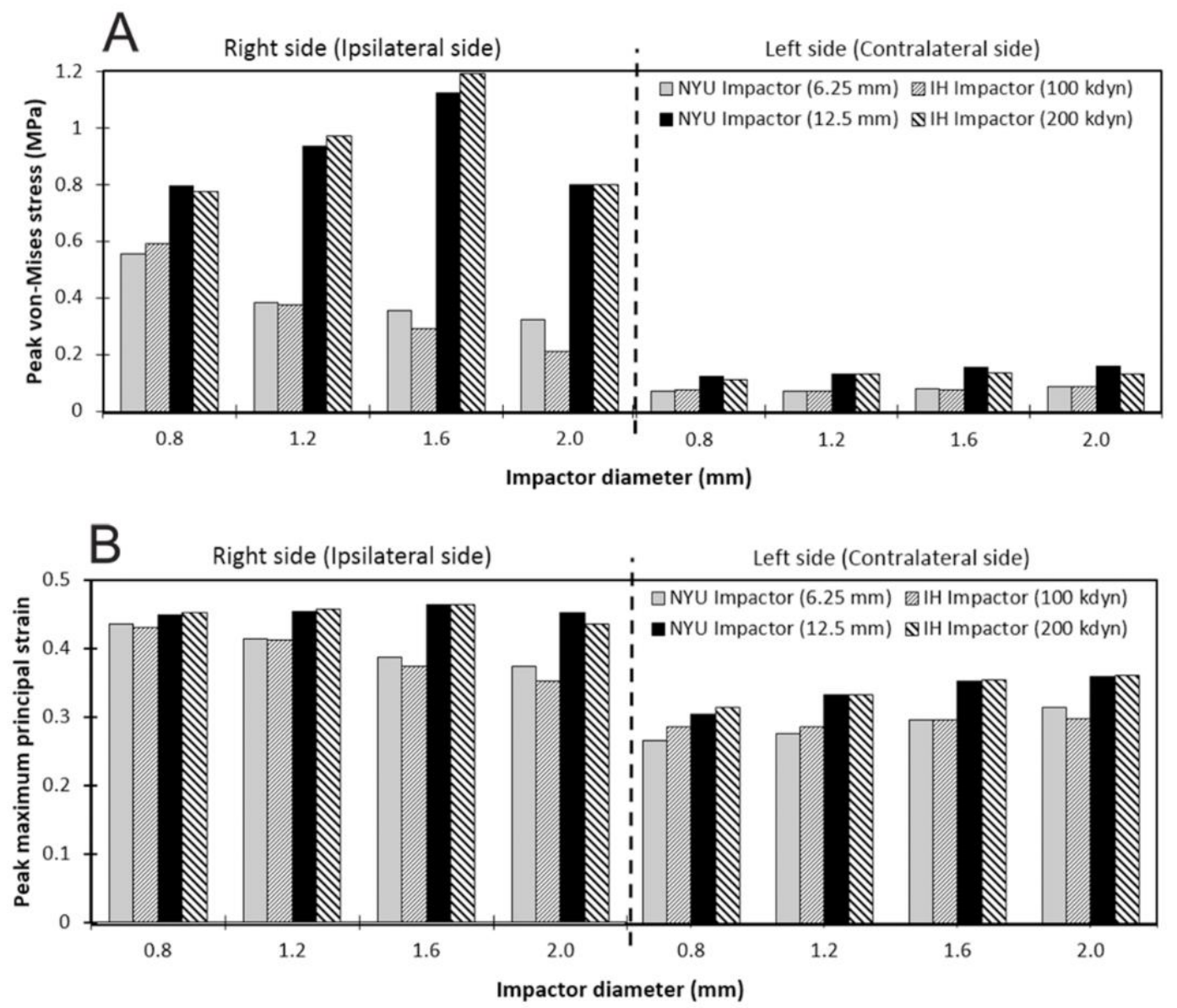

Figure 3. (A) Peak von-Mises stress and (B) maximum principal strain in the right and left side of the spinal cord for the New York University (NYU) and Infinite Horizon (IH) impactors at impactor tip diameters of $0.8 \mathrm{~mm}, 1.2 \mathrm{~mm}, 1.6 \mathrm{~mm}$, and $2.0 \mathrm{~mm}$. 


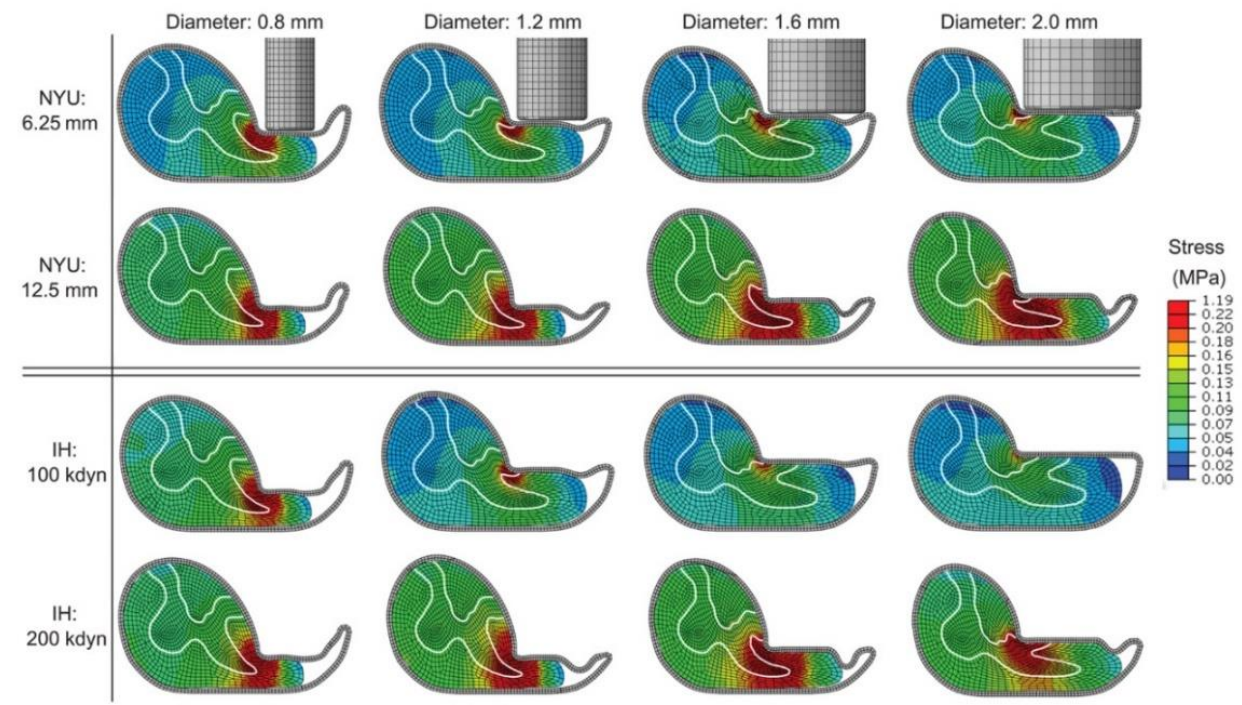

Figure 4. Stress distributions in the transverse view at the maximum compression for the NYU and IH impactors at impactor tip diameters of $0.8 \mathrm{~mm}, 1.2 \mathrm{~mm}, 1.6 \mathrm{~mm}$, and $2.0 \mathrm{~mm}$.

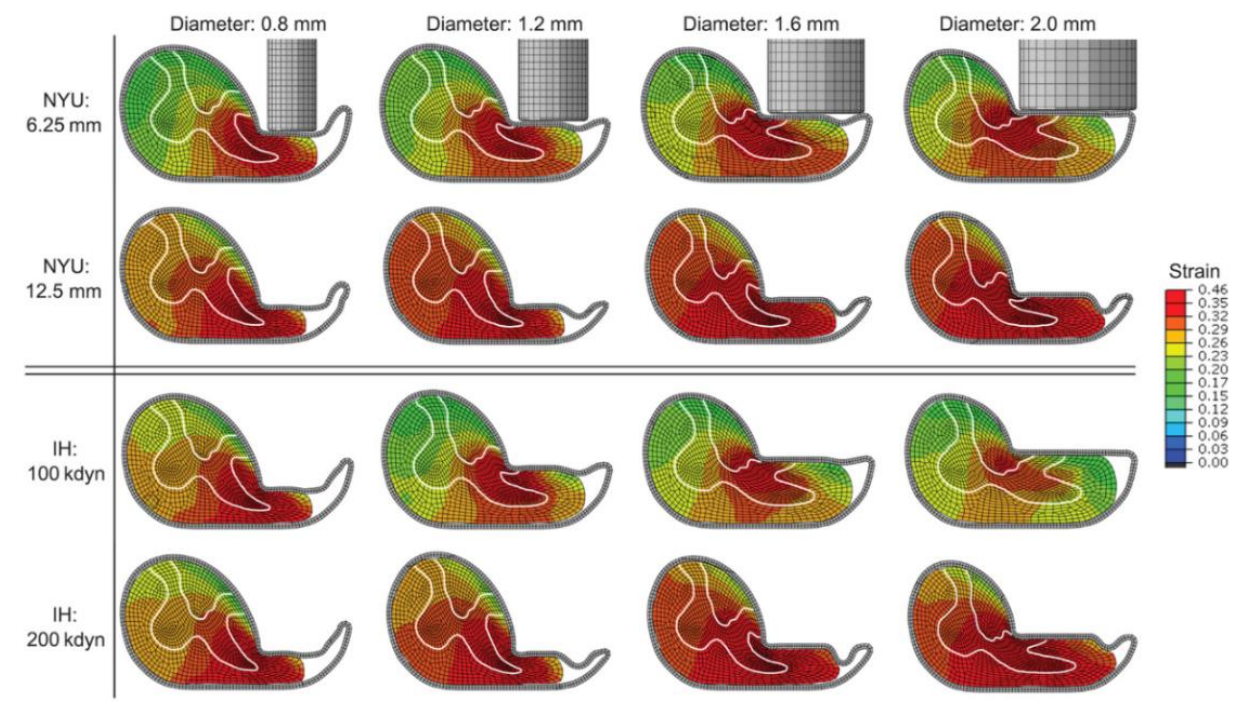

Figure 5. Strain distributions in the transverse view at the maximum compression for the NYU and IH impactors at impactor tip diameters of $0.8 \mathrm{~mm}, 1.2 \mathrm{~mm}, 1.6 \mathrm{~mm}$, and $2.0 \mathrm{~mm}$.

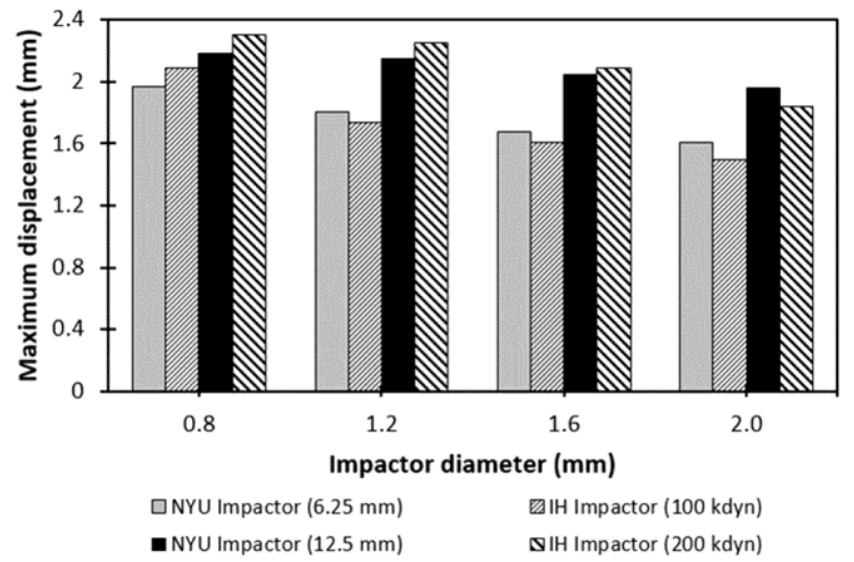

Figure 6. The maximum displacement of the spinal cord for the NYU and IH impactors at impactor tip diameters of $0.8 \mathrm{~mm}, 1.2 \mathrm{~mm}, 1.6 \mathrm{~mm}$, and $2.0 \mathrm{~mm}$. 


\section{Discussion}

In this study, the influence of impactor tip diameters on stresses, strains, and displacement in the spinal cord were investigated and quantified for NYU and IH impactors. The stress and strains on the ipsilateral side of the spinal cord occurred with a $1.6 \mathrm{~mm}$ diameter impactor with the $12.5 \mathrm{~mm}$ NYU impactor and $200 \mathrm{kdyn} \mathrm{IH}$ impactor. In addition, the larger impactor tip resulted in increased stress and strain to the contralateral side, which is consistent with Gensel's study [12], showing that a larger impactor tip produced lesions that spread to the side contralateral to the injury; thus, the impactor tip diameter was reduced from 2.5 to $2.0 \mathrm{~mm}$. In previous experimental studies, an impactor tip diameter ranging from $0.8 \mathrm{~mm}$ to $2.0 \mathrm{~mm}$ was used for the hemicontusion SCI models; however, producing consistent ipsilateral injury was difficult in some cases because of problems related to mechanical impact $[11,12,15-17,20,22]$. Lee et al. [16] reported that some of the experiments failed to produce severe or sustained functional deficits, and damage in the spinal cord was placed too far laterally because the impactor tip was hitting the vertebral column or a lateral movement of the cord occurred during the experiment. Thus, they reported a modified model with a $22.5^{\circ}$ rotation to more directly impact (perpendicularly) the spinal cord without so much lateral displacement [16]. The spinal cord FE model with a rotation could resolve the problem related to mechanical impact with a smaller impactor tip, such as less lateral movement, and showed more uniform stress and strain in the cord. The results from the present study showed that the impactor tip diameter of $0.8 \mathrm{~mm}$ resulted in higher penetration into tissue but lower stresses and strains within the cord, because the cord laterally shifted and the force missed the spinal cord. Impactor tip diameters from 1.2 to $1.6 \mathrm{~mm}$ are appropriate for the cervical hemicontusion SCI rat model without damaging the contralateral side of the spinal cord.

The NYU impactor at the drop height of $6.25 \mathrm{~mm}$ showed less stress and strain than that with the drop height of $12.5 \mathrm{~mm}$, regardless of the impactor diameter, as the experimental study by Walker et al. [37] showed that the $25.0 \mathrm{~mm}$ drop height produced greater damage than the $12.5 \mathrm{~mm}$ drop height. The NYU impactor at the drop height of $12.5 \mathrm{~mm}$ and the IH impactor at the force of $200 \mathrm{kdyn}$ resulted in dramatically higher stress and strain, especially at the ipsilateral or contused side of the spinal cord. The $12.5 \mathrm{~mm}$ case resulted in 1.4-3.2 times higher stress than the $6.25 \mathrm{~mm}$ case, while the 200 kdyn case resulted in 1.3-4.1 times higher stress than the $100 \mathrm{kdyn}$ case. Previous in vivo studies have reported that the graded ipsilateral tissue sparing, including white and gray matter damage, was directly related to injury severity in the hemicontusion SCI model using IH [11] and NYU [12] impactors. Dunham et al. [11] showed that ipsilateral white matter area was reduced by approximately $10 \%$ when the impact force was increased by $100 \mathrm{kdyn}$ for the IH impactor. Soblosky et al. [9] presented that the white and gray matter area at the epicenter of injury was reduced by 1.7-2.2 and 1.2-2.0 times for moderate and severe unilateral SCI, respectively. Gensel et al. [12] reported that ipsilateral tissue damage at the lesion center was two times higher in the $12.5 \mathrm{~mm}$ group, compared to in the $6.25 \mathrm{~mm}$ group. They also found that anatomical damage was isolated to the spinal cord ipsilateral to the injury since less than $2 \%$ of the contralateral damage was detected. The FE model showed that stress and strain in the ipsilateral side were significantly higher than in the contralateral side of the spinal cord, which showed similar trends in the severity of injury. Thus, the FE model could be considered to mimic the histological outcomes in the in vivo studies, but a more accurate representation of the spinal cord tissues is required to properly correlate the simulation results with the experimental findings [33].

In addition, the results showed that the NYU impactor was similar to the IH impactor for hemicontusion injury. The maximum stresses of $0.32 \mathrm{MPa}$ and $0.79 \mathrm{MPa}$ with the $6.25 \mathrm{~mm}$ and $12.5 \mathrm{~mm}$ NYU impactors were similar to the $0.21 \mathrm{MPa}$ and $0.80 \mathrm{MPa}$ stresses with the $100 \mathrm{kdyn}$ and $200 \mathrm{kdyn}$ $\mathrm{IH}$ impactors with a $2.0 \mathrm{~mm}$ impactor tip diameter, respectively. These results were comparable with previous data from a central contusion SCI model [31] showing 0.26 MPa and 0.63 MPa stresses with $6.25 \mathrm{~mm}$ and $12.5 \mathrm{~mm}$ NYU impactors, and $0.14 \mathrm{MPa}$ and $0.5 \mathrm{MPa}$ stresses with $100 \mathrm{kdyn}$ and $200 \mathrm{kdyn}$ IH impactors with a $2.5 \mathrm{~mm}$ impactor tip diameter, respectively. The relationship between the NYU and IH devices also remained for the hemicontusion model as shown in the central contusion model [31], although slightly different values were obtained. 
The predicted spinal cord displacements showed a trend similar to trends reported elsewhere; spinal cord displacement increased with increasing injury severity or decreasing impactor size $[11,12,15,38]$. Under IH impactor experimental conditions, the FE model showed an impactor displacement of $2.0 \mathrm{~mm}$ at an impact force of $200 \mathrm{kdyn}$ with a $1.6 \mathrm{~mm}$ diameter impactor, and an impactor displacement of $1.7 \mathrm{~mm}$ at an impact force of $100 \mathrm{kdyn}$ with a $1.2 \mathrm{~mm}$ diameter impactor. These results are comparable with impactor displacements of 1.6 to $1.8 \mathrm{~mm}$ at an impact force of $200 \mathrm{kdyn}$ with a $1.6 \mathrm{~mm}$ impactor tip diameter [15]. In addition, Alvarez-Argote et al. [38] showed displacements of 0.57 to $1.56 \mathrm{~mm}$ at an impact force of $100 \mathrm{kdyn}$ with a $1.3 \mathrm{~mm}$ impactor tip diameter. Furthermore, the stress and strain distributions in the cord, and spinal cord deformations inside the spinal canal, were similar to those in the previous FE model of unilateral injury in the rat, which also showed an impact force of $2.53 \mathrm{~N}$ for $1.6 \mathrm{~mm}$ displacement with a $1.6 \mathrm{~mm}$ diameter impactor [32]. The experimental data demonstrated that the spinal cord displacements at drop heights of $6.25 \mathrm{~mm}$ and $12.5 \mathrm{~mm}$ for the NYU impactor were 1.8 to $2.3 \mathrm{~mm}$ and 2.4 to $2.9 \mathrm{~mm}$, respectively, while our model showed approximate displacements of $1.6 \mathrm{~mm}$ and $2.0 \mathrm{~mm}$ at drop heights of $6.25 \mathrm{~mm}$ and $12.5 \mathrm{~mm}$, respectively. These studies are in agreement with our results, despite some differences in experimental conditions.

There are several limitations to our study. Only the $6.25 \mathrm{~mm}$ and $12.5 \mathrm{~mm}$ cases were considered for the NYU impactor, and $100 \mathrm{kdyn}$ and $200 \mathrm{kdyn}$, for the IH impactor, due to the low animal survival rates reported with increasing impact forces [17]. Gensel et al. [12] showed that with the NYU impactor, all animals survived with an impact height of 6.25 or $12.5 \mathrm{~mm}$. However, an impact force of $300 \mathrm{kdyn}$ resulted in significantly fewer surviving neurons in the spinal cord than impact forces of 100-200 kdyn for the IH device [11]. The model geometries were simplified, as in previous modeling studies of the spinal cord $[23,31,39]$. The impactor tip was modeled with a rounded shape since it can provide more uniform strain with lower peak magnitude, and a substantially enhanced temporal window for the study of cellular injury mechanisms [40]. The homogeneous material properties were used for the white and gray matter in the spinal cord, which could affect the results. The fluid flow was not considered in this study because the inclusion of fluid flow has little effect on impact [39]. Furthermore, the impactor rod was placed $1.0 \mathrm{~mm}$ from the midline, although no behavioral differences were observed between the injuries at $1.0 \mathrm{~mm}$ to $1.4 \mathrm{~mm}$ off the midline [16]. Sensitivity analysis for the impact position on the spinal cord could enhance the confidence of this study. Finally, the results from the FE model should be compared with the data from the in vivo experiments in order to confirm the results of this study.

In conclusion, we investigated the effects of impactor size in the hemicontusion SCI model for NYU and IH impactors. The stresses and strains on the ipsilateral side of the spinal cord were dependent on both impact load and impactor tip diameter. Impactor tip diameters of $1.2 \mathrm{~mm}$ and $1.6 \mathrm{~mm}$ with high impact loading resulted in the highest stresses and strains on the ipsilateral side. Thus, impactor tip diameters between $1.2 \mathrm{~mm}$ and $1.6 \mathrm{~mm}$ would be convenient to use in the rat hemicontusion SCI models for the cervical region without damaging the contralateral side of the spinal cord. Our study provides an insight into hemicontusion SCI models in the rat.

Author Contributions: Conceptualization, B.K., K.K. and Y.H.K.; methodology, B.K., K.K. and Y.H.K.; software, B.K.; validation, B.K., K.K., T.B. and Y.H.K.; formal analysis, B.K., K.K. and Y.H.K.; investigation, B.K., K.K. and Y.H.K.; resources, Y.H.K.; data curation, B.K. and K.K.; writing-original draft preparation, B.K. and K.K.; writing-review and editing, B.K., K.K., T.B. and Y.H.K.; visualization, B.K.; supervision, Y.H.K.; project administration, K.K. and Y.H.K.; funding acquisition, K.K. and Y.H.K. All authors have read and agreed to the published version of the manuscript.

Funding: This work was supported by a grant from Kyung Hee University in 2018 (KHU-20181173).

Conflicts of Interest: The authors declare no conflict of interest.

\section{References}

1. Sekhonm, L.H.; Fehlings, M.G. Epidemiology, demographics, and pathophysiology of acute spinal cord injury. Spine 2001, 26, S2-S12. [CrossRef] [PubMed] 
2. Noyes, D.H. Electromechanical impactor for producing experimental spinal cord injury in animals. Med. Biol. Eng. Comput. 1987, 25, 335-340. [CrossRef] [PubMed]

3. Constantini, S.; Young, W. The effects of methylprednisolone and the ganglioside GM1 on acute spinal cord injury in rats. J. Neurosurg. 1994, 80, 97-111. [CrossRef] [PubMed]

4. Basso, D.M.; Beattie, M.S.; Bresnahan, J.C. Graded histological and locomotor outcomes after spinal cord contusion using the NYU weight-drop device versus transection. Exp. Neurol. 1996, 139, 244-256. [CrossRef] [PubMed]

5. Scheff, S.W.; Rabchevsky, A.G.; Fugaccia, I.; Main, J.A.; Lumpp, J.E., Jr. Experimental modeling of spinal cord injury: Characterization of a force-defined injury device. J. Neurotrauma 2003, 20, 179-193. [CrossRef]

6. Rabchevsky, A.G.; Sullivan, P.G.; Fugaccia, I.; Scheff, S.W. Creatine diet supplement for spinal cord injury: Influences on functional recovery and tissue sparing in rats. J. Neurotrauma 2003, 20, 659-669. [CrossRef]

7. Ghasemlou, N.; Kerr, B.J.; David, S. Tissue displacement and impact force are important contributors to outcome after spinal cord contusion injury. Exp. Neurol. 2005, 196, 9-17. [CrossRef]

8. Nishi, R.A.; Liu, H.; Chu, Y.; Hamamura, M.; Su, M.Y.; Nalcioglu, O.; Anderson, A.J. Behavioral, histological, and ex vivo magnetic resonance imaging assessment of graded contusion spinal cord injury in mice. J. Neurotrauma 2007, 24, 674-689. [CrossRef]

9. Soblosky, J.S.; Song, J.H.; Dinh, D.H. Graded unilateral cervical spinal cord injury in the rat: Evaluation of forelimb recovery and histological effects. Behav. Brain Res. 2001, 119, 1-13. [CrossRef]

10. Pearse, D.D.; Lo, T.P., Jr.; Cho, K.S.; Lynch, M.P.; Garg, M.S.; Marcillo, A.E.; Sanchez, A.R.; Cruz, Y.; Dietrich, W.D. Histopathological and behavioral characterization of a novel cervical spinal cord displacement contusion injury in the rat. J. Neurotrauma 2005, 22, 680-702. [CrossRef]

11. Dunham, K.A.; Siriphorn, A.; Chompoopong, S.; Floyd, C.L. Characterization of a graded cervical hemicontusion spinal cord injury model in adult male rats. J. Neurotrauma 2010, 27, 2091-2106. [CrossRef] [PubMed]

12. Gensel, J.C.; Tovar, C.A.; Hamers, F.P.; Deibert, R.J.; Beattie, M.S.; Bresnahan, J.C. Behavioral and histological characterization of unilateral cervical spinal cord contusion injury in rats. J. Neurotrauma 2006, 23, 36-54. [CrossRef] [PubMed]

13. Anderson, K.D.; Sharp, K.G.; Steward, O. Bilateral cervical contusion spinal cord injury in rats. Exp. Neurol. 2009, 220, 9-22. [CrossRef] [PubMed]

14. Aguilar, R.M.; Steward, O. A bilateral cervical contusion injury model in mice: Assessment of gripping strength as a measure of forelimb motor function. Exp. Neurol. 2010, 221, 38-53. [CrossRef]

15. Sandrow-Feinberg, H.R.; Izzi, J.; Shumsky, J.S.; Zhukareva, V.; Houle, J.D. Forced exercise as a rehabilitation strategy after unilateral cervical spinal cord contusion injury. J. Neurotrauma 2009, 26, 721-731. [CrossRef]

16. Lee, J.H.; Streijger, F.; Tigchelaar, S.; Maloon, M.; Liu, J.; Tetzlaff, W.; Kwon, B.K. A contusive model of unilateral cervical spinal cord injury using the infinite horizon impactor. J. Vis. Exp. 2012, 65, e3313. [CrossRef]

17. Streijger, F.; Beernink, T.M.; Lee, J.H.; Bhatnagar, T.; Park, S.; Kwon, B.K.; Tetzlaff, W. Characterization of a cervical spinal cord hemicontusion injury in mice using the infinite horizon impactor. J. Neurotrauma 2013, 30, 869-883. [CrossRef] [PubMed]

18. Mondello, S.E.; Sunshine, M.D.; Fischedick, A.E.; Moritzm, C.T.; Horner, P.J. A cervical hemi-contusion spinal cord injury model for the investigation of novel therapeutics targeting proximal and distal forelimb functional recovery. J. Neurotrauma 2015, 32, 1994-2007. [CrossRef]

19. Ungerer, G.; Cui, J.; Ndam, T.; Bekemeier, M.; Song, H.; Li, R.; Siedhoff, H.R.; Yang, B.; Appenteng, M.K.; Greenlief, C.M.; et al. Harpagophytum procumbens extract ameliorates allodynia and modulates oxidative and antioxidant stress pathways in a rat model of spinal cord injury. Neuromol. Med. 2020, 22, 278-292. [CrossRef]

20. Popovich, P.G.; Lemeshow, S.; Gensel, J.C.; Tovar, C.A. Independent evaluation of the effects of glibenclamide on reducing progressive hemorrhagic necrosis after cervical spinal cord injury. Exp. Neurol. 2012, 233, 615-622. [CrossRef]

21. Simard, J.M.; Popovich, P.G.; Tsymbalyuk, O.; Gerzanich, V. Spinal cord injury with unilateral versus bilateral primary hemorrhage-Effects of glibenclamide. Exp. Neurol. 2012, 233, 829-835. [CrossRef] [PubMed]

22. Nicaise, C.; Hala, T.J.; Frank, D.M.; Parker, J.L.; Authelet, M.; Leroy, K.; Brion, J.P.; Wright, M.C.; Lepore, A.C. Phrenic motor neuron degeneration compromises phrenic axonal circuitry and diaphragm activity in a unilateral cervical contusion model of spinal cord injury. Exp. Neurol. 2012, 235, 539-552. [CrossRef] [PubMed]

23. Maikos, J.T.; Qian, Z.; Metaxas, D.; Shreiber, D.I. Finite element analysis of spinal cord injury in the rat. J. Neurotrauma 2008, 25, 795-816. [CrossRef] [PubMed] 
24. Khuyagbaatar, B.; Kim, K.; Kim, Y.H. Effect of bone fragment impact velocity on biomechanical parameters related to spinal cord injury: A finite element study. J. Biomech. 2014, 44, 2820-2825. [CrossRef] [PubMed]

25. Khuyagbaatar, B.; Kim, K.; Park, W.M.; Lee, S.; Kim, Y.H. Increased stress and strain on the spinal cord due to ossification of the posterior longitudinal ligament in the cervical spine under flexion after laminectomy. Proc. Inst. Mech. Eng. Part H 2017, 231, 898-906. [CrossRef]

26. Greaves, C.Y.; Gadala, M.S.; Oxland, T.R. A threedimensional finite element model of the cervical spine with spinal cord: An investigation of three injury mechanisms. Ann. Biomed. Eng. 2008, 36, 396-405. [CrossRef]

27. Khuyagbaatar, B.; Kim, K.; Park, W.M.; Kim, Y.H. Effect of posterior decompression extent on biomechanical parameters of the spinal cord in cervical ossification of the posterior longitudinal ligament. Proc. Inst. Mech. Eng. Part H 2016, 230, 545-552. [CrossRef]

28. Russell, C.M.; Choo, A.M.; Tetzlaff, W.; Chung, T.E.; Oxland, T.R. Maximum principal strain correlates with spinal cord tissue damage in contusion and dislocation injuries in the rat cervical spine. J. Neurotrauma 2012, 29, 1574-1585. [CrossRef]

29. Khuyagbaatar, B.; Kim, K.; Purevsuren, T.; Lee, S.H.; Kim, Y.H. Biomechanical effects on cervical spinal cord and nerve root following laminoplasty for ossification of the posterior longitudinal ligament in the cervical spine: A comparison between open-door and double-door laminoplasty using finite element analysis. J. Biomech. Eng. 2018, 140, 071006. [CrossRef]

30. Lam, C.J.; Assinck, P.; Liu, J.; Tetzlaff, W.; Oxland, T.R. Impact depth and the interaction with impact speed affect the severity of contusion spinal cord injury in rats. J. Neurotrauma 2014, 31, 1985-1997. [CrossRef]

31. Khuyagbaatar, B.; Kim, K.; Kim, Y.H. Conversion Equation between the Drop Height in the New York University Impactor and the Impact Force in the Infinite Horizon Impactor in the Contusion Spinal Cord Injury Model. J. Neurotrauma 2015, 32, 1987-1993. [CrossRef] [PubMed]

32. Sparrey, C.J.; Salegio, E.A.; Camisa, W.; Tam, H.; Beattie, M.S.; Bresnahan, J.C. Mechanical design and analysis of a unilateral cervical spinal cord contusion injury model in non-human primates. J. Neurotrauma 2016, 33, 1136-1149. [CrossRef] [PubMed]

33. Fournely, M.; Petit, Y.; Wagnac, E.; Evin, M.; Arnoux, P.J. Effect of experimental, morphological and mechanical factors on the murine spinal cord subjected to transverse contusion: A finite element study. PLoS ONE 2020, 15, e0232975. [CrossRef] [PubMed]

34. Laing, A.C.; Brenneman, E.C.; Yung, A.; Liu, J.; Kozlowski, P.; Oxland, T. The effects of age on the morphometry of the cervical spinal cord and spinal column in adult rats: An MRI-based study. Anat. Rec. 2014, 297, 1885-1895. [CrossRef] [PubMed]

35. Jaumard, N.V.; Leung, J.; Gokhale, A.J.; Guarino, B.B.; Welch, W.C.; Winkelstein, B.A. Relevant anatomic and morphological measurements of the rat spine: Considerations for rodent models of human spine trauma. Spine 2015, 40, E1084-E1092. [CrossRef]

36. Khuyagbaatar, B.; Kim, K.; Park, W.M.; Kim, Y.H. Biomechanical investigation of post-operative C5 palsy due to ossification of the posterior longitudinal ligament in different types of cervical spinal alignment. J. Biomech. 2017, 57, 54-61. [CrossRef]

37. Walker, C.L.; Zhang, Y.P.; Liu, Y.; Li, Y.; Walker, M.J.; Liu, N.K.; Shields, C.B.; Xu, X.M. Anatomical and functional effects of lateral cervical hemicontusion in adult rats. Restor. Neurol. Neurosci. 2016, 34, 389-400. [CrossRef]

38. Alvarez-Argote, S.; Gransee, H.M.; Mora, J.C.; Stowe, J.M.; Jorgenson, A.J.; Sieck, G.C.; Mantilla, C.B. The impact of midcervical contusion injury on diaphragm muscle function. J. Neurotrauma 2016, 33, 500-509. [CrossRef]

39. Persson, C.; Summers, J.; Hall, R.M. The importance of fluid-structure interaction in spinal trauma models. J. Neurotrauma 2011, 28, 113-125. [CrossRef]

40. Pleasant, J.M.; Carlson, S.W.; Mao, H.; Scheff, S.W.; Yang, K.H.; Saatman, K.E. Rate of neurodegeneration in the mouse controlled cortical impact model is influenced by impactor tip shape: Implications for mechanistic and therapeutic studies. J. Neurotrauma 2011, 28, 2245-2262. [CrossRef]

(C) 2020 by the authors. Licensee MDPI, Basel, Switzerland. This article is an open access article distributed under the terms and conditions of the Creative Commons Attribution (CC BY) license (http://creativecommons.org/licenses/by/4.0/). 